\title{
Remembering Michael Stephen Feld: Physics and Biomedicine Pioneer (1940-2010)
}

\section{Introduction}

Michael Feld ranged over a wide intellectual landscape. During his more than 50 years in physics and biomedicine, he pioneered on several frontiers. His career began with fundamental discoveries in laser science and ended as he was producing exciting, innovative developments in biomedical optics and biomedical physics.

Feld enjoyed crossing boundaries and savored diversity of ideas, of research fields, of colleagues, and of collaborators. His taste for intellectual variety was in notable contrast to his fixed and long association with the Massachusetts Institute of Technology (MIT). He entered MIT in 1958 as an undergraduate, and except for a junior year in England, he never left. Even when he took a sabbatical, he took it at MIT. It is as though his firm anchor to one institution freed his imagination and research to span many fields.

Michael Feld had a gift for building collaborations across disciplines. He was director of MIT's Harrison Spectroscopy Laboratory from 1976 until his death on April 10, 2010, and he made the Spectroscopy Laboratory a place that welcomed scientists of all ages and nationalities and from many disciplines (see Fig. 1). Under his direction, the laboratory became a center for a variety of productive collaborations. He institutionalized and increased funding for such cooperative research by establishing, with National Science Foundation (NSF) support, the MIT Regional Laser Research Facility, and, with support from the National Institutes of Health $(\mathrm{NIH})$, the Laser Biomedical Research Center (LBRC). He worked closely with collaborators from the Cleveland Clinic and from Massachusetts General Hospital. He was an affiliated member of the MIT-Harvard Health Sciences and Technology (HST) program and supervised the doctoral work of men and women in that program and also in chemical engineering, bioengineering, and materials research, as well as in physics. Many of his former students and postdocs have become leaders in health science or physics.

\section{Research}

In the later part of his career, Feld became known for innovative applications of laser spectroscopy to biomedicine and biomedical engineering. In collaboration with his postdoctoral associates and students, he developed the spectroscopic examination of cells and tissue, new kinds of microscopy, and novel uses of electric fields to study cell behavior. They have used these tools along with fluorescence and Raman spectroscopy to examine biological tissues and detect disease via endoscopy and optical tomography. ${ }^{1}$

In 1985, Feld showed that fluorescence could be used to diagnose atherosclerosis and that work opened the field of spectral diagnosis of disease. The LBRC provided a framework within which he did research that developed further medical applications of spectroscopy. The applications included use of Raman spectroscopy by Feld and his collaborators to diagnose atherosclerosis and breast cancer and to make noninvasive blood glucose measurements. They went on to develop multimodal spectroscopy techniques for diagnosing and imaging cervical and oral neoplasia, and they developed 3-D tomographic microscopy for imaging living cells.

Feld's research interests began with basic laser science. Ali Javan, inventor of the $\mathrm{He}-\mathrm{Ne}$ laser, supervised Feld's PhD thesis, ${ }^{2}$ and the two worked together in the 1960s-the golden age of laser physics. Feld's results on laser-induced line narrowing of coupled Doppler-broadened transitions were important to the development of Doppler-free two-photon spectroscopy. After he became a member of the MIT faculty in 1968, he continued to work on basic laser science. In 1973 , he made the first experimental observations of superradiance: the spontaneous collective emission of radiation from an assemblage of excited atoms. ${ }^{3}$ Later he directed a series of experiments on the radiation of a single isolated atom in an optical resonator. These resulted in the first demonstration of enhanced spontaneous emission and radiative level shifts in an open optical resonator and in the development of the single-atom laser. ${ }^{4,5}$

Always interested in novel applications of lasers, Feld collaborated with nuclear physicists to measure laser-induced optical emissions from radioactive atoms. These experiments were done in the Spectroscopy Laboratory with radioactive sources and showed that laser interactions with atomic electrons could alter the spatial pattern of the radiations emitted by the atoms' nuclei. ${ }^{6,7}$ This work influenced at least one nuclear physics laboratory to produce exotic atoms with a heavy-ion accelerator and study them with laser spectroscopy.

\section{Biography}

Michael Stephen Feld was born November 11, 1940 to Lillian (neé Rosenberg) and Albert Norwalk. His father died a few years later; his mother remarried, and her husband Joseph Feld adopted Michael, and his last name became Feld. Michael's half-brother Peter R. Feld was born April 12, 1946 and died in 1991.

Michael grew up on Long Island and graduated from Lynbrook High School ("home of the Fighting Owls") in 1958. He showed an early inclination toward science. His lifelong friend Robert Gold recalls that Michael tutored him through high school physics. Even then Michael showed a lack of a sense of time. "We used to make pools on how late Michael would be for any event.... He once came six hours late to a New Year's party.... He lived in his own time zone."8

In the fall of 1958, he enrolled in MIT as an undergraduate. He spent the academic year 1960-1961 at University College London studying philosophy and physics. He graduated from MIT in 1963. Showing his characteristic breadth of interests, he submitted a thesis that satisfied the requirements for both an SB degree in humanities and sciences and an SM degree in physics. ${ }^{9}$ He stayed on to earn a PhD in physics in 1967 , and in 1968, he became an assistant professor in MIT's department of physics. 


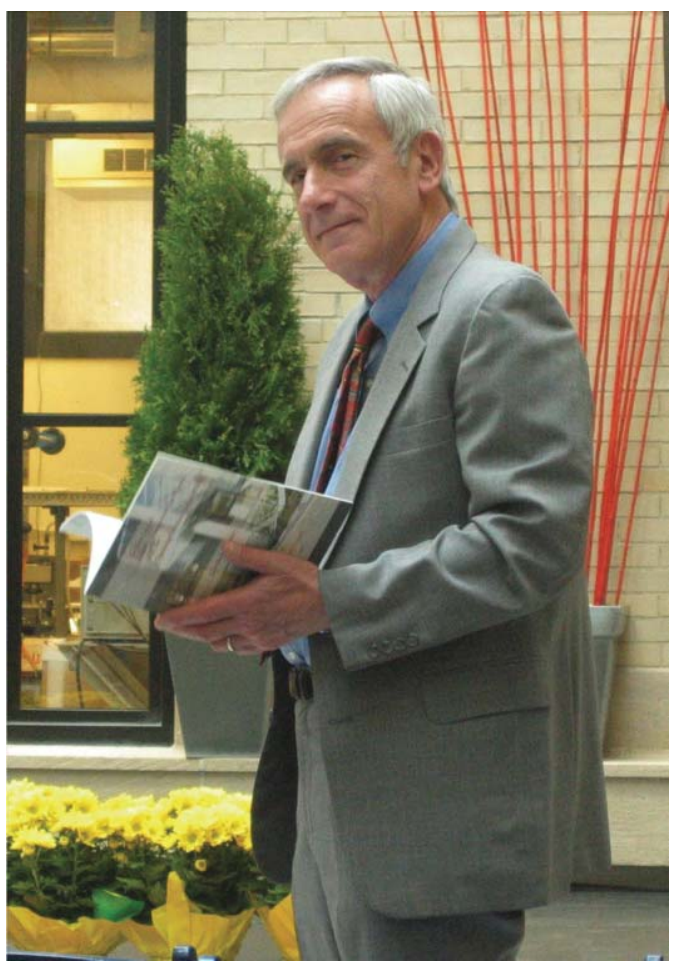

Fig. 1 Michael Feld dedicating renovated space for MIT's Harrison Spectroscopy Laboratory in October 2007.

In 1963, he married Mary Haskell, his high school sweetheart, and in 1964, they became parents of twin boys, Jonathan and David. The marriage ended in 1975. In 1980, Feld and Frances Aschheim married. Their daughter Alexandra was born in 1983. The couple separated in 2001 and divorced a few years later. In 2005, Feld married Alison Hearn, who survives him. She continues to teach, play music, and work at MIT.

He took fatherhood seriously. His sons recall him visiting their school to do science demonstrations for their classmates; he and the boys launched Estes rockets. He introduced them to karate when they were eight years old, and the boys advanced more quickly than he, and began to teach him. Fran Aschheim recalls that in 1999 when Alexandra's ballet studio put on the Nutcracker, "...Michael took the stage as Mother Ginger (in full drag regalia)... He took this as seriously as if he were playing Hamlet, and he loved every minute... At the least provocation, he would perform."

\section{Honors and Prizes}

Feld received the Thompson Award in 1991 for the development of biomedical Raman spectroscopy, and the Vinci d'Excellence (France) in 1995 for development of the singleatom laser. In 1992, he was the Wolk Visitor and Lecturer at Colgate University. He was 1996 Distinguished Baetjer Colloquium speaker at Princeton University. In 2003, he received the Lamb Medal of the Physics of Quantum Electronics Conference for the first experimental demonstrations of superradiance and the microlaser, and for pioneering applications of optics to biological physics. In 2008, the Optical Society of America gave him its prestigious William F. Meggers Award in recognition of his major contributions to the foundations of laser spectroscopy and his pioneering developments in the application of spectroscopy to biomedicine.

\section{Personal}

Michael worked on other frontiers as well. He was an early and persistent leader of efforts to make MIT a community that welcomed minorities. With Leo Osgood, Jr., he persuaded the Institute to establish the Dr. Martin Luther King, Jr. Visiting Professor Program. He was proud of his role in establishing this program, which has brought more than 70 visiting professors and scholars to participate actively in the intellectual life of MIT.

He particularly valued his experience with Ronald McNair, and in that association his pupil became his teacher. Michael supervised McNair's thesis work, ${ }^{10}$ and McNair taught him and his twin sons karate. Michael earned a brown belt; Jonathan and David became black belts. McNair's death in the 1986 explosion of the Challenger Space Shuttle was a deep personal loss for Michael.

It was typical of Michael that once he had begun a project like learning karate, he would merge it with his interest in physics and push it to its limits. He liked to tell how, having agreed to give a Christmas lecture on the physics of karate, "...I was gripped with terror-I realized that I had just agreed to give a lecture on a topic I knew nothing about! Motivated by fear, I began a crash research program, including taking strobe movies of karate strikes." The results were presentations at two national meetings of the American Association for the Advancement of Science (AAAS), two published articles about the physics of karate-one in Scientific American ${ }^{11,12}$ and freshman physics students who were delighted by his classroom demonstration of breaking a stack of eight boards with his fist (Fig. 2).

Michael had an antic side. He liked to tell about running with (or, perhaps better to say, "near") the bulls at Pamplona; Joel Parks or John Kramer can tell you more. John Thomas tells of returning from Australia (Fig. 3) with Michael: "Mike liked to rib the homeland security people, usually by not taking off his shoes, but this time he had another idea. He bought a Swiss army knife and wanted to take it in his carry-on bag, not check it with his luggage." And Alison can tell you about the time that he conspired with the prospective groom to send a

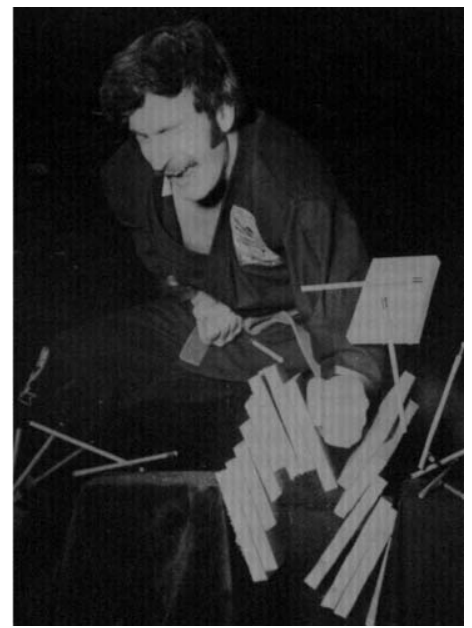

Fig. 2 Kareto Michael Feld breaking boards with a hammer; fist blow c. 1978 


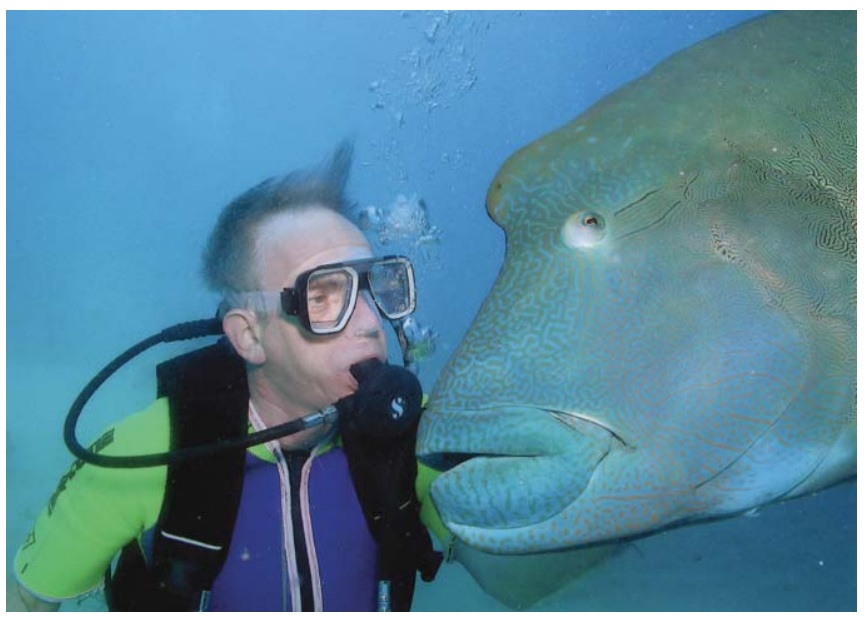

Fig. 3 Feld develops a collaboration with a humphead wrasse in Australia in 2003.

male stripper into the rather sedate wedding shower that was being given for her friend.

Robert Gold has stories too: In high school, Michael organized a group of friends-"the luncheon club"-that went to the house of whoever's parents weren't at home and raided the refrigerator. Michael would write a report on the refrigerator contents and give them a grade. "My mother was really irked when he gave her a B."

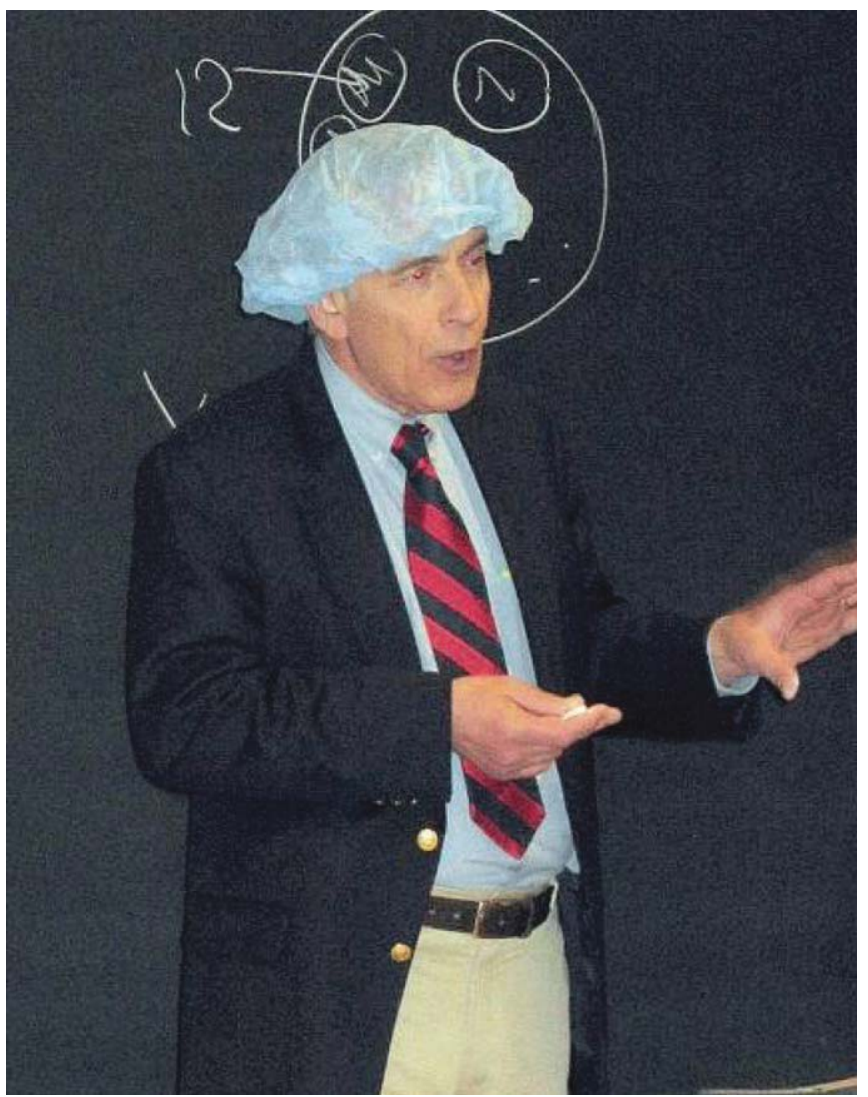

Fig. 4 Feld leads a 2007 seminar discussion after the speaker modeled clean-room garb.

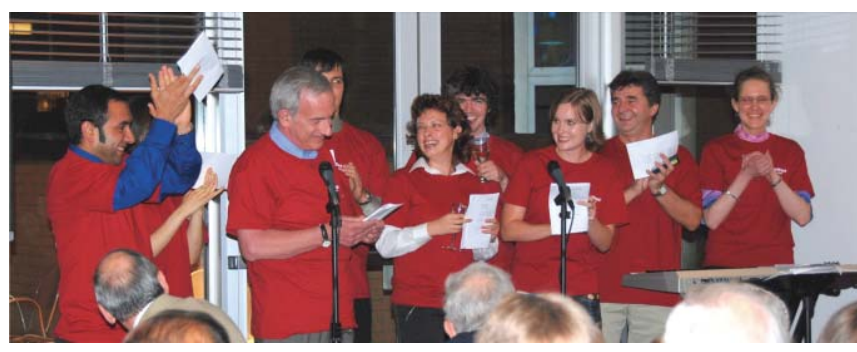

Fig. 5 The Spectratones in July 2007. Left to Right: G. P. Singh, Michael Feld, Obrad Scepanovic, Zoya Volynskaya, Geoff O'Donoghue, Kate Bechtel, Gabi Popescu, and Alison Hearn.

Michael Feld was a workaholic. He worked long hours, skipped meals, stayed up all night to meet deadlines, and drove his students and colleagues hard. He was a demanding mentor-refrigerator contents were not the only things he criticized. He held long meetings with little sense of how much time was passing.

He also worked hard to build group esprit and to impart a sense of common purpose to the research done in the Spectroscopy Laboratory. He created and published The Spectrograph, the lab's semiannual newsletter. He fostered the Modern Optics Seminar series, which brings outstanding practitioners to the lab to discuss their work with students (Fig. 4) and faculty and to socialize with them over pizza. $\mathrm{He}$ found funding for and instituted the annual Lord Lecture at which an eminent scientist describes groundbreaking work.

On the social side, Feld organized summer outings to the seashore or a lake. There were frequent parties to welcome or say farewell to visitors, to honor graduating students, or to celebrate some major achievement within the lab. One of his favorite creations was the laboratory singing group, "The Spectratones" (see Fig. 5). At Spec Lab celebrations they sang physics words to familiar pop tunes, making up with wit and enthusiasm for what they lacked in tunefulness.

One of Feld's most important steps for enriching the intellectual and social lives of his students and colleagues was to recruit Ramachandra Rao Dasari as associate director of the Spectroscopy Laboratory. For over 30 years, they worked together to create a warm, open, and accommodating atmosphere that supported student learning, vigorous innovative research, and wide-ranging collaborations. Their complementary social, administrative, scientific, and mentoring skills made the lab flourish.

\section{Conclusion}

Michael Feld died of complications arising from multiple myeloma. He knew since 2002 that he had this fatal disease, but characteristically he squeezed a great deal of life and work from the eight years that intensive medical care was able to give him. He married; he traveled three times to Australia, to India, and several times to Europe and Japan; he oversaw the PhD thesis work of a dozen students; and he (and they) published some 90 articles. (Over his entire career, he supervised approximately $50 \mathrm{PhDs}$ and was an author on more than 360 publications.) It is no surprise that he also collaborated with his personal physician to study his disease; he used his own final illness to advance medical research. 
A man of singular energy, will, and vision, Michael Feld had a powerful effect on all who knew him-his family, his colleagues, his students, the MIT community, and his coworkers in the professions of physics and biomedicine. His career spanned a half century of great social and scientific change both at MIT and in the larger communities of the nation and the world. His adaptability and vision made him an active agent of those changes. Feld's life was in its entirety a grand collaboration that has left a body of scientific work of lasting value, a large cadre of former students and postdocs shaped by their interactions with Michael Feld to carry on and lead the next generation of work that he began, and a legion of friends and family who are grateful for his life and his time with them.

\section{Charles H. Holbrow Colgate University Massachusetts Institute of Technology}

\section{References}

1. For a complete listing of Feld's publications go to (http://web.mit.edu/spectroscopy/research/publications.html).

2. M. S. Feld, "Spectroscopic studies of atomic oxygen using gas laser techniques," PhD Thesis, Massachusetts Institute of Technology, Cambridge (1967).
3. N. Skribanowitz, I. P. Herman, J. C. MacGillivray, and M.S. Feld, "Observation of Dicke superradiance in optically pumped HF gas," Phys. Rev. Lett. 30, 309-312 (1973).

4. K. An., J. J. Childs, R. R. Dasari, and M. S. Feld, "Microlaser-a laser with one-atom in an optical-resonator," Phys. Rev. Lett. 73, 3375-3378 (1994).

5. M. S. Feld and K. W. An, "The single-atom laser," Sci. Am. 279(7), 56-63 (1998).

6. G. Shimkaveg, W. W. Quivers, R. R. Dasari, C. H. Holbrow, P. G. Pappas, M. A. Attili, J. E. Thomas, D. E. Murnick, and M.S. Feld, "Laser-induced nuclear orientation of $1-\mu \mathrm{s}$ Rb-85m," Phys. Rev. Lett. 53, 2230-2233 (1984).

7. J. Mackin, R. R. Dasari, C. H. Holbrow, J. T. Hutton, D. E. Murnick, M. Otteson, W. W. Quivers, Jr., G. Shimkaveg, and M. S. Feld, "Sub-doppler nuclear detection of laser-induced orientation of ${ }^{85} \mathrm{Rb}^{\mathrm{m}}$," Phys. Rev. Lett. 66, 1681-1684 (1991).

8. R. Gold, private communication (2010).

9. M. S. Feld, "Absorption spectroscopy using optical masers: Including a discussion of early investigations into the process of stimulated emission of radiation," Master's Thesis submitted to the Department of Humanities and the Department of Physics, Massachusetts Institute of Technology, (http://hdl.handle.net/1721.1/49598) (1963).

10. R. E. McNair, "Energy absorption and vibrational heating in molecules following intense laser excitation," PhD Thesis, Massachusetts Institute of Technology (1977).

11. S. R. Wilk, R. E. McNair, and M. S. Feld, "The physics of karate," Am. J. Phys. 51, 783-790 (1983).

12. M. S. Feld, R. E. McNair, and S. R. Wilk, "The techniques of karate," Sci. Am. 240(4), 150-158 (1979). 